\title{
Arabidopsis mesophyll protoplasts: a versatile cell system for transient gene expression analysis
}

\author{
Sang-Dong Yoo ${ }^{1,2}$, Young-Hee Cho ${ }^{1,2} \&$ Jen Sheen ${ }^{1,2}$ \\ ${ }^{1}$ Department of Molecular Biology, Massachusetts General Hospital, Boston, Massachusetts, USA. ${ }^{2}$ Department of Genetics, Harvard Medical School, Boston, \\ Massachusetts 02114, USA. Correspondence should be addressed to S.-D.Y. (yoo@molbio.mgh.harvard.edu).
}

Published online 21 June 2007; corrected after print 11 October 2013; doi:10.1038/nprot.2007.199

The transient gene expression system using Arabidopsis mesophyll protoplasts has proven an important and versatile tool for conducting cell-based experiments using molecular, cellular, biochemical, genetic, genomic and proteomic approaches to analyze the functions of diverse signaling pathways and cellular machineries. A well-established protocol that has been extensively tested and applied in numerous experiments is presented here. The method includes protoplast isolation, PEG-calcium transfection of plasmid DNA and protoplast culture. Physiological responses and high-throughput capability enable facile and cost-effective explorations as well as hypothesis-driven tests. The protoplast isolation and DNA transfection procedures take 6-8 $\mathrm{h}$, and the results can be obtained in 2-24 h. The cell system offers reliable guidelines for further comprehensive analysis of complex regulatory mechanisms in whole-plant physiology, immunity, growth and development.

\section{INTRODUCTION}

Plant protoplasts without cell walls offer a versatile cell-based experimental system. Macromolecules such as DNA, RNA and proteins can be delivered into protoplasts using various methods, e.g., PEG-calcium fusion, electroporation and microinjection. Signal transduction and metabolic pathways as well as transcription and translation machineries can be transiently manipulated to investigate cell-autonomous regulation and responses. The method is especially powerful in functional genomics analysis when combined with rich genetic resources, such as insertion libraries, available in the model plant Arabidopsis thaliana. We describe here a protocol for a system of transient expression in Arabidopsis mesophyll protoplast (TEAMP) and provide troubleshooting advice and detailed information on useful reporter constructs. Applications, advantages and limitations of the TEAMP assay are also discussed. More general information about plant protoplasts can be found in a review ${ }^{1}$ and a live performance of the TEAMP procedure can be seen at the Sheen lab website (http://genetics. mgh.harvard.edu/sheenweb/protocols_reg.html).

Overview

The isolation of plant protoplasts was first reported more than 40 years ago $^{2}$. Protoplasts had been used to observe cellular processes and activities such as cell wall synthesis, cell division, embryogenesis, differentiation during regeneration, photosynthesis activity, calcium signaling and regulation, and the modulation of ion channels by light, stress and hormone responses in various plant species ${ }^{1}$. Protoplasts were also isolated from special cell types to investigate cell type-specific responses. For example, gibberellin and abscisic acid actions on $\alpha$-amylase synthesis and blue light-induced $\mathrm{H}^{+}$-ATPase activity have been studied with protoplasts isolated from barley aleurone layer ${ }^{3}$ and Vicia faba guard cells ${ }^{4}$, respectively.

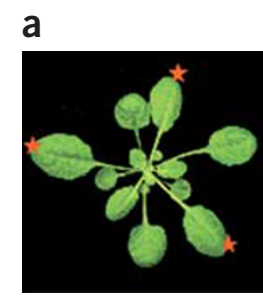
gene construct.
After the development and significant improvement of various DNA transfection methods (e.g., PEG, electroporation and microinjection), diverse cellular functions of genes of interest have been studied using protoplasts generated from several plant species ${ }^{1}$. Since Arabidopsis became the central model system in plant biology with the availability of its whole genome sequence, we and several other laboratories have established the TEAMP system as a cellbased functional genomics tool ${ }^{1,5}$.

The TEAMP protocol is based on mesophyll protoplasts freshly isolated from leaves of Arabidopsis wild-type or mutant plants growing on soil (see Fig. 1a). After cell walls are removed using fungal cellulase and macerozyme, protoplasts are released, washed and collected (see Fig. 1b,c). Remarkably, these protoplasts maintain many of the same physiological responses and cellular activities as intact plants, despite the enzymatic treatment step $^{1}$. PEGcalcium-mediated transfection is used to deliver DNA into protoplasts, followed by $2-24 \mathrm{~h}$ incubation to allow gene expression (see Fig. 1d). A sterile technique is not necessary owing to the short incubation time. To allow constitutive expression of transfected
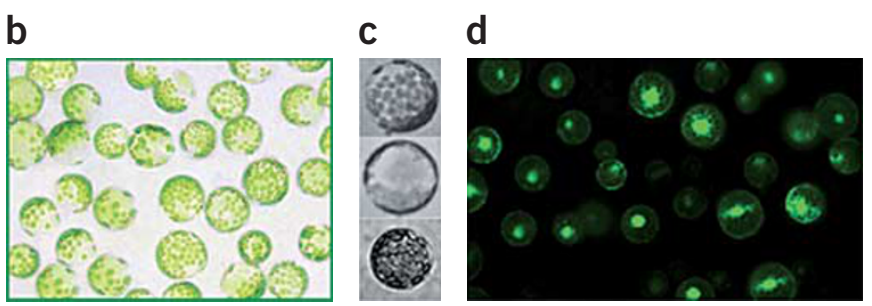

Figure 1 | Arabidopsis protoplast isolation and transient gene expression. (a) A healthy 4-week-old Arabidopsis plant suitable for protoplast isolation. Asterisks indicate the optimal true leaves (fifth, sixth and seventh) to be used as a mesophyll protoplast source. (b) Mesophyll protoplasts $(\times 400)$. (c) Isolated protoplasts retain the characteristics of the genetic backgrounds from which they were obtained; protoplasts isolated from wild-type Col-0 (top), ethylene-insensitive etr1-1 mutant (middle) and the constitutive ethylene response ctr1-1 mutant (bottom) show different cellular morphology and characteristics under light microscopy $(\times 600)$. (d) Protoplasts expressing the nuclear-targeted GFP driven by the constitutive $35 \mathrm{~S}$ enhancer fused to the maize C4PPDK basal promoter are shown under fluorescence microscopy $(\times 400)$. More than $90 \%$ of protoplasts were transfected successfully with the GFP reporter 
genes, the cauliflower mosaic virus $35 \mathrm{~S}$ promoter derivative with the maize $C 4 P P D K$ basal promoter and the $5^{\prime}$ untranslated region $\left(5^{\prime}\right.$-UTR) enhancer is used $^{6}$ (see Fig. 2a). To control the level of gene expression, a chemically inducible gene expression system has also been developed (see Advantages and limitations).

Luciferase $^{7}$ (LUC) and $\beta$-glucuronidase ${ }^{8}$ (GUS) are routinely used as reporters for the quantitative measurement of gene expression in TEAMP assays (Fig. $\mathbf{2 b}$, Table 1). A set of LUC reporters controlled by diverse promoters that can respond to specific signals (Table 1) have been donated by the Sheen lab to the public stock center, the Arabidopsis Biological Resource Center (ABRC). These reporters can serve as positive controls to help set up the TEAMP assay in laboratories new to the system. However, the application of TEAMP is not limited to reporter assays. Physiological and cell-autonomous responses can be observed and scored using various analytical methods to investigate protein activity, localization, trafficking, interaction and stability.

\section{Applications}

Physiological and cell-autonomous responses and assays in protoplasts have been widely used to identify key regulators and elucidate molecular mechanisms underlying intracellular signal transduction pathways involved in plant physiology, immunity, growth and development. The application of TEAMP system has been significantly broadened in recent years and will be further expanded by integration with Arabidopsis genomics and genetic resources for high-throughput explorations.

Using TEAMP assays, molecular mechanisms underlying plant hormone signaling pathways have been elucidated. In auxin signaling, regulatory functions and responses of AUX/IAA proteins ${ }^{9}$, RAC GTPase ${ }^{10}$ and auxin response factors ${ }^{11}$ have been characterized. The protein stability control of EIN3, a key nuclear transcription factor in ethylene signaling, has been shown to be the main regulatory event involved in an unexpected crosstalk between glucose and ethylene signaling ${ }^{12}$. Significantly, the phospho-relay via the Arabidopsis two-component system has been established as the main cytokinin regulatory circuitry ${ }^{13}$, which has been verified by numerous genetic and phenotypic analyses of corresponding Arabidopsis mutants ${ }^{14}$. Both abiotic and biotic stress signaling can also be studied in the TEAMP system. For example, the functions of the evolutionarily conserved mitogen-activated protein kinase (MAPK) cascades have been identified and characterized in Arabidopsis mesophyll protoplasts for oxidative stress signaling ${ }^{5}$ and innate immune responses ${ }^{15}$. Subsequently, the virulence functions of type III effectors, AvrPto and AvrPtoB from the pathogenic bacterium Pseudomonas syringae, have been shown to be potent suppressors of the MAPK-dependent plant innate immunity ${ }^{16}$.

More recently, protein-protein interactions in vivo between the glucose sensor hexokinase 1 (HXK1) and its partners have been demonstrated for HXK1-dependent nuclear glucose signaling ${ }^{17}$. Through application of the yeast two-hybrid concept,

TABLE 1 | List of useful reporter constructs for transient expression in Arabidopsis mesophyll protoplast assays.

\begin{tabular}{|c|c|c|c|c|c|}
\hline Name & GenBank locus & $\begin{array}{l}\text { Arabidopsis Biological Resource } \\
\text { Center stock number }\end{array}$ & Promoter of interest (POI) & Use & References \\
\hline pHBT-sGFP(S65T)-NOS & EF090408 & CD3-911 & $35 \mathrm{~S}$ derivative & Transfection control & 19 \\
\hline pRD29A-LUC-NOS & EF090409 & CD3-912 & At5g52310 & Abscisic acid response & 5,13 \\
\hline pWRKY29-LUC-NOS & EF090411 & CD3-914 & At4g23550 & Bacterial flg22 response & 15 \\
\hline pGST6-LUC-NOS & EF090412 & CD3-915 & At2g47730 & General stress response & 5 \\
\hline pHSP18.2-LUC-NOS & EF090413 & CD3-916 & At5g59720 & Heat response & 13 \\
\hline pGCC1-LUC-NOS & EF090415 & CD3-918 & $8 \times G C C$ box synthetic promoter & Ethylene response & 12 \\
\hline pFRK1-LUC-NOS & EF090416 & CD3-919 & At2g19190 & Bacterial flg22 response & 16 \\
\hline
\end{tabular}


protein-protein interaction has also been examined in Arabidopsis mesophyll protoplasts to establish a heterodimerization map of specific groups of bZIP transcription factors ${ }^{18}$.

Single-cell imaging of diverse fluorescence marker proteins, e.g., GFP and its variants, fused to functional proteins have also been extensively utilized to examine protein localizations, protein domain functions in protein targeting and protein transport machinery functions in vesicle trafficking. For instance, subcellular localization of various proteins has been determined using the GFP $\operatorname{tag}^{11,12,17-19}$. Novel roles of the transmembrane domain and C-terminal 7 amino acids of Arabidopsis small outer envelope membrane protein 7 have been identified for chloroplast targeting $^{20}$. Interesting regulatory roles of dynamin-like ADL6 (ref. 21), small GTP binding protein Rhal (ref. 22) and actin filaments ${ }^{23}$ have been studied in vacuolar trafficking. The protoplast isolation method and fluorescence-assisted cell sorting technique have been further applied to reveal genome-wide cell type-specific transcript profiles in Arabidopsis roots ${ }^{24}$.

\section{Advantages and limitations}

Uniform and abundant mesophyll protoplasts isolated from mature Arabidopsis leaves can respond to diverse signals in a physiological manner similar to the responses observed in leaves of whole plants. Importantly, application of the TEAMP system is not limited to processes and activities that occur in leaves. Proteins that are normally expressed in other cell types and tissues can be ectopically expressed and examined in mesophyll protoplasts to learn their molecular and cellular functions. Analysis using mesophyll protoplasts often provides information of greater functional and physiological relevance to plants than data obtained using heterologous cell systems, e.g., bacteria, yeast, insect and mammalian cells. As most of the quantitative and physiological responses can be observed and measured within 2-10 $\mathrm{h}$ after DNA transfection, the experiments do not require sterile techniques and complex culture medium, which represents a tremendous saving in time and costs. There is no other biological system for gene expression analysis (including bacterial, yeast and mammalian cell culture) that can be handled with the same minimal laboratory requirement. The requirement for a relatively small number of protoplasts is another advantage of the TEAMP system owing to its high efficiency and sensitivity. In some other protoplast protocols, $10-1,000$ times more protoplasts $\left(10^{5}-10^{7}\right)$ are recommended for each DNA transfection experiment ${ }^{25}$.

On the other hand, the conserved functions of molecular domains and regulatory mechanisms among bacteria, yeasts, animals and plants allow us to utilize molecular switches, originally identified in other organisms, to control gene and protein expression levels in plant mesophyll protoplasts. For instance, the mammalian steroid nuclear receptor has been used to provide a ligand inducible gene expression system in mesophyll protoplasts ${ }^{12}$. As depicted in Figure 2c, an artificial transcription activator (ATA) is constructed with a bacterial DNA-binding domain (LexA-DB), a viral transcription activation domain (VP16) and a mammalian (rat) glucocorticoid receptor $(G R)$. The ATA is driven under the constitutive $35 \mathrm{~S}$ enhancer fused to the maize $C 4 P P D K$ basal promoter $^{6}$. Upon dexamethasone (DEX) treatment, the ATA (LexA-VP16-GR) is released from the cytoplasm HSP90 complex and moves into the nucleus to induce target gene transcription ${ }^{26}$.
In the nucleus, the ATA controls the transcription of a DNA construct that is driven by eight copies of the bacterial LexA operator $(8 \times L e x A-O P)$ and the minimum $35 \mathrm{~S}$ promoter (see Fig. 2c). In the example presented (in which the LUC reporter gene is included in the $8 x L$ exA-OP-driven construct; see Fig. 2d), LUC expression is induced upon DEX treatment and shows linear expression kinetics. The expression level of LUC is also controlled in a ligand dosage-dependent manner, indicating that the expression level of desired genes and proteins can be manipulated using this inducible system.

Mesophyll protoplasts can be isolated from fresh leaves of wild-type and most Arabidopsis mutant plants and used immediately for experiments without the time-consuming step of cell culture establishment. Wild-type mesophyll protoplasts maintain most leaf features and responses, which are often lost in undifferentiated suspension culture cells. The mutant protoplasts possess the cellular nature that is characteristic of the original mutant plants. For example, mesophyll protoplasts isolated from the ethylene-insensitive etr1-1 and the constitutive ethyleneresponse ctr1-1 mutants show cellular morphology and characteristics distinct from those in the wild type (see Fig. 1c). There are many successful examples of using the TEAMP assay with various mutant plants, including the analysis of ARF7 functions in auxin signaling ${ }^{11}$, the antagonistic interaction between HXK1dependent glucose and ethylene signaling ${ }^{12}$, the receptor kinase FLS2 function in flg22 signaling ${ }^{15}$ and roles of various plant hormone signaling pathways in programmed cell death induced by the fungal toxin fumonisin B1 (ref. 27). Conceptually, the use of protoplasts generated from mutant plants in TEAMP assays to screen for new regulators is similar to performing mutant suppressor or enhancer screens, which are commonly applied in the genetic analysis of specific signaling pathways. In general, it is necessary empirically to optimize the protoplast isolation and DNA transfection conditions for different Arabidopsis accessions and mutants. Once conditions are optimized, the use of genetically diverse mesophyll protoplasts makes the TEAMP system even more powerful in functional genomics research.

Unlike plant and animal cell culture lines, mesophyll protoplasts do not divide in the simple incubation buffer described in this protocol. Thus, this TEAMP protocol is not suitable for the study of cell cycle regulation. To use protoplasts to study cell division and dedifferentiation or other long-term plant responses, specialized plant growth conditions and sterile culture media will be required. Such protoplast regeneration protocols have been developed over the past two decades as well ${ }^{28-30}$.

For successful experiments, a high level of protoplast transfection efficiency (greater than 50\%) is very important to obtain reliable and reproducible data using the TEAMP system. We recommend the use of an improved GFP vital marker donated to the ABRC to visually monitor protoplast transfection efficiency ${ }^{19}$ (see Fig. 1d). Careful practice, keen observation and accumulated experience contribute to the acquisition of meaningful results. All experiments need to be repeated multiple times to ensure consistency and to avoid pitfalls and false positive results. Even though the protocol appears to be simple and straightforward, the importance of practice and empirical optimization of each experiment for the individual researcher's purpose cannot be overemphasized. 
MATERIALS

REAGENTS

•0.2 M 4-morpholineethanesulfonic acid (MES, pH 5.7; Sigma, cat. no. M8250), sterilize using a $0.45-\mu \mathrm{m}$ filter

- 0.8 M mannitol (Sigma, cat. no.M4125), sterilize using a $0.45-\mu \mathrm{m}$ filter - $1 \mathrm{M} \mathrm{CaCl}_{2}$ (Sigma, cat. no. C7902), sterilize using a $0.45-\mu \mathrm{m}$ filter

$\cdot 2 \mathrm{M} \mathrm{KCl}$ (Sigma, cat. no. P3911), sterilize using a $0.45-\mu \mathrm{m}$ filter

- $2 \mathrm{M} \mathrm{MgCl}_{2}$ (Sigma, cat. no. M9272), sterilize using a $0.45-\mu \mathrm{m}$ filter

- $\beta$-Mercaptoethanol (Sigma, cat. no. M6250)

- 10\% (wt/vol) BSA (Sigma, cat. no. A-6793), sterilize using a $0.45-\mu \mathrm{m}$ filter

- Cellulase R10 (Yakult Pharmaceutical Ind. Co., Ltd., Japan)

- Macerozyme R10 (Yakult Pharmaceutical Ind. Co., Ltd., Japan)

$\triangle$ CRITICAL We have obtained the best results with this enzyme provider.

- PEG4000 (Fluka, cat. no. 81240) $\Delta$ CRITICAL We found that the PEG source is very critical to achieve high transfection efficiency.

- 1 M Tris-phosphate ( $\mathrm{pH} 7.8$ ), sterilize using a $0.45-\mu \mathrm{m}$ filter

- $100 \mathrm{mM}$ trans-1,2-diaminocyclo-hexane- $N, N, N^{\prime}, N^{\prime}$-tetraacetic acid

(DACTAA; Sigma, cat. no. D-1383)

-50\% (vol/vol) glycerol (Fisher, cat. no. 15892), sterilize using a $0.45-\mu \mathrm{m}$ filter

$\cdot 20 \%$ (vol/vol) Triton X-100 (Sigma, cat. no. T-8787)

- 1 M DTT (Sigma, cat. no. D-9779)

- LUC assay system (Promega, cat. no. E1501)

- 1 M Tris-HCl (pH 8.0) (US Biological, cat. no. T8650), sterilize using a $0.45-\mu \mathrm{m}$ filter

•0.1 M 4-methylumbelliferyl glucuronide (MUG; Gold BioTechnology, Inc., cat. no. $\mathrm{MUG}-1 \mathrm{G})$

$\cdot 0.2 \mathrm{M} \mathrm{Na}_{2} \mathrm{CO}_{3}$ (Sigma, cat. no. S7795)

-1 M methylumbelliferone (MU; Fluka, cat. no. 69580)

- Metro-Mix 360 (Sun Gro Horticulture, Inc.)

- Jiffy7 (Jiffy Products Ltd., Canada)

- Arabidopsis accessions: Col-0 and Ler (ABRC)

- Enzyme solution (see REAGENT SETUP)

-Washing and incubation (WI) solution (see REAGENT SETUP)

-W5 solution (see REAGENT SETUP)

- MMG solution (see REAGENT SETUP)

-PEG-calcium transfection solution (see REAGENT SETUP)

- Protoplast lysis buffer (see REAGENT SETUP)

- MUG substrate mix for GUS assay (see REAGENT SETUP)

-Ampicillin

\section{EQUIPMENT}

- Fluorescence microscope (Leica DM5000; Leica)

- Luminometer (Monolite3010; Pharmigen)

- Fluorometer (TK100; Hoefer)

- Bench-top centrifuge (IEC Centra CL2; International Equipment Company)

$\cdot 0.45-\mu \mathrm{m}$ syringe sterilization filter (Whatman, cat. no. 6870-2504)
- Generic razor blade (single-edged blade; VWR Scientific, cat. no. 55411-055)

- Petri dish $\left(100 \times 25 \mathrm{~mm}^{2}\right.$ for $10 \mathrm{ml}$ enzyme solution; VWR Scientific, cat. no. 25389-000)

- Nylon mesh (75 $\mu \mathrm{m}$, laboratory sifters, Carolina Biological Supplies, cat. no. $65-2222 \mathrm{~N}$ )

-Improved Neubauer 0.1-mm-deep Reichert hemacytometer (Hausser

Scientific, cat. no. 1483)

-30-ml round-bottomed tube (Sarstedt, cat. no. 55.517)

-2-ml round-bottomed natural microcentrifuge tube (SealRite; USA Scientific, cat. no. $1620-2700)$

-6-well culture dish (Falcon, cat. no. 3046)

REAGENT SETUP

Enzyme solution Prepare $20 \mathrm{mM}$ MES (pH 5.7) containing 1.5\% (wt/vol) cellulase R10, 0.4\% (wt/vol) macerozyme R10, $0.4 \mathrm{M}$ mannitol and $20 \mathrm{mM} \mathrm{KCl}$ Warm the solution at $55^{\circ} \mathrm{C}$ for $10 \mathrm{~min}$ to inactivate DNAse and proteases and enhance enzyme solubility. Cool it to room temperature $\left(25^{\circ} \mathrm{C}\right)$ and add $10 \mathrm{mM}$ $\mathrm{CaCl}_{2}, 1-5 \mathrm{mM} \beta$-mercaptoethanol (optional) and $0.1 \%$ BSA. $\triangle$ CRITICAL Addition of $1-5 \mathrm{mM} \beta$-mercaptoethanol is optional, and its use should be determined according to the experimental purpose. $\triangle$ CRITICAL Before the enzyme powder is added, the MES solution is preheated at $70{ }^{\circ} \mathrm{C}$ for $3-5 \mathrm{~min}$. The final enzyme solution should be clear light brown. Filter the final enzyme solution through a $0.45-\mu \mathrm{m}$ syringe filter device into a Petri dish $\left(100 \times 25 \mathrm{~mm}^{2}\right.$ for $10 \mathrm{ml}$ enzyme solution). $\Delta$ CRITICAL The enzyme solution should be prepared fresh.

WI solution Prepare $4 \mathrm{mM}$ MES ( $\mathrm{pH}$ 5.7) containing $0.5 \mathrm{M}$ mannitol and $20 \mathrm{mM} \mathrm{KCl}$. The prepared WI solution can be stored at room temperature $\left(22-25{ }^{\circ} \mathrm{C}\right)$.

W5 solution Prepare 2 mM MES (pH 5.7) containing $154 \mathrm{mM} \mathrm{NaCl}, 125 \mathrm{mM}$ $\mathrm{CaCl}_{2}$ and $5 \mathrm{mM} \mathrm{KCl}$. The prepared $\mathrm{W} 5$ solution can be stored at room temperature.

MMG solution Prepare 4 mM MES (pH 5.7) containing $0.4 \mathrm{M}$ mannitol and $15 \mathrm{mM} \mathrm{MgCl}_{2}$. The prepared MMG solution can be stored at room temperature. PEG-calcium transfection solution Prepare 20-40\% (wt/vol) PEG4000 in $\mathrm{ddH}_{2} \mathrm{O}$ containing $0.2 \mathrm{M}$ mannitol and $100 \mathrm{mM} \mathrm{CaCl}_{2}$. $\Delta$ CRITICAL Prepare PEG solution at least $1 \mathrm{~h}$ before transfection to completely dissolve PEG. The PEG solution can be stored at room temperature and used within $5 \mathrm{~d}$. However, freshly prepared PEG solution gives relatively better protoplast transfection efficiency. Do not autoclave PEG solution.

Protoplast lysis buffer Prepare $25 \mathrm{mM}$ Tris-phosphate ( $\mathrm{pH} 7.8)$ containing $1 \mathrm{mM}$ DTT, $2 \mathrm{mM}$ DACTAA, 10\% (vol/vol) glycerol and $1 \%$ (vol/vol) Triton $\mathrm{X}-100$. The lysis buffer should be prepared fresh.

MUG substrate mix for GUS assay Prepare $10 \mathrm{mM}$ Tris- $\mathrm{HCl}(\mathrm{pH} 8)$ containing $1 \mathrm{mM} \mathrm{MUG}$ and $2 \mathrm{mM} \mathrm{MgCl}$. The prepared GUS assay substrate can be stored at $-20{ }^{\circ} \mathrm{C}$

\section{PROCEDURE}

\section{Plant growth $\bigcirc$ TIMING 3-4 weeks}

1) Grow Arabidopsis plants on either Metro-Mix 360 or Jiffy7 soil in a greenhouse or an environment-controlled chamber with a relatively short photoperiod $\left(10-13 \mathrm{~h}\right.$ light at $23^{\circ} \mathrm{C} / 11-14 \mathrm{~h}$ dark at $\left.20{ }^{\circ} \mathrm{C}\right)$ under low light $\left(50-75 \mu \mathrm{E} \mathrm{m}^{-2} \mathrm{~s}^{-1}\right)$ and $40-65 \%$ relative humidity.

$\triangle$ CRITICAL STEP Col-0 and Ler have been extensively tested in our lab. In general, Arabidopsis plants are very sensitive to all kinds of environmental changes (e.g., drought, flooding, extreme temperature and constant mechanical perturbation). Try to maintain a constant environment as much as possible.

\section{Protoplast isolation TIMING 4-5 h}

2| Choose well-expanded leaves from 3-4-week-old plants (usually true leaf numbers five to seven) before flowering (see Fig. 1a).

$\triangle$ CRITICAL STEP The selection of healthy leaves at the proper developmental stage is a very important factor in protoplast experiments. Protoplasts prepared from leaves recovered from stress conditions (e.g., drought, flooding, extreme temperature and constant mechanical perturbation) may look similar to those from healthy leaves. However, we have often experienced low transfection efficiency with the protoplasts from stressed leaves. High stress-induced cellular status can also be a problem in the study of stress, defense and hormonal signaling pathways.

3| Cut 0.5-1-mm leaf strips from the middle part of a leaf using a fresh sharp razor blade without tissue crushing at the cutting site. A good preparation yields approximately $10^{7}$ protoplasts per gram fresh weight (approximately 100-150 leaves 
digested in 40-60 ml of enzyme solution). For routine experiments, 10-20 leaves digested in 5-10 ml enzyme solution will give $0.5-1 \times 10^{6}$ protoplasts, enough for more than $25-100$ samples $\left(1-2 \times 10^{4}\right.$ protoplasts per sample).

$\triangle$ CRITICAL STEP Change the blade after cutting four to five leaves. We routinely cut leaves on a piece of clean white paper $\left(8^{\prime \prime} \times 11^{\prime \prime}\right)$ on top of the solid and clean laboratory bench, which provides for good support and easy inspection of wounded/crushed tissue (juicy and dark green stain).

4 Transfer leaf strips quickly and gently into the prepared enzyme solution (10-20 leaves in 5-10 $\mathrm{ml}$ ) by dipping both sides of the strips (completely submerged) using a pair of flat-tip forceps.

$\triangle$ CRITICAL STEP Immediate dipping and submerging of leaf strips is very critical for protoplast yield. When leaf strips are dried out on the paper during cutting, the enzyme solution cannot penetrate and protoplast yield is decreased significantly.

5| Vacuum infiltrate leaf strips for $30 \mathrm{~min}$ in the dark using a desiccator.

6| Continue the digestion, without shaking, in the dark for at least $3 \mathrm{~h}$ at room temperature. The enzyme solution should turn green after a gentle swirling motion, which indicates the release of protoplasts.

$\triangle$ CRITICAL STEP Digestion time depends on the experimental goals, desirable responses and materials used, and it needs to be optimized empirically. After $3 \mathrm{~h}$ digestion, most protoplasts are released from leaf strips in case of Col- 0 . However, the protoplast isolation efficiency differs significantly for different ecotypes and genotypes. The digesting time has to be optimized for each ecotype and genotype. Prolonged incubation of leaves $(16-18 \mathrm{~h})$ in the dark is stressful and might eliminate physiological responses of leaf cells. However, the stress might be important for the dedifferentiation and regeneration processes recommended in other protoplast protocols.

7| Check for the release of protoplasts in the solution under the microscope; the size of Arabidopsis mesophyll protoplasts is approximately $30-50 \mu \mathrm{m}$.

$\triangle$ CRITICAL STEP It is not necessary to release all the protoplasts from leaf strips. Be gentle with protoplasts, but you can handle them with regular pipettes and pipette tips.

8| Dilute the enzyme/protoplast solution with an equal volume of W5 solution before filtration to remove undigested leaf tissues.

9| Wash a clean $75-\mu \mathrm{m}$ nylon mesh with water to remove ethanol (the mesh is normally kept in $95 \%$ ethanol) then remove excess water before protoplast filtration. Filter the enzyme solution containing protoplasts after wetting the $75-\mu \mathrm{m}$ nylon mesh with W5 solution.

10 Centrifuge the flow-through at $100 \mathrm{~g}$ to pellet the protoplasts in a 30-ml round-bottomed tube for 1-2 min. Remove as much supernatant as possible and re-suspend the protoplast pellet by gentle swirling.

$\triangle$ CRITICAL STEP A higher speed (200g) of centrifugation may help to increase protoplast recovery. ? TROUBLESHOOTING

11 Re-suspend protoplasts at $2 \times 10^{5} \mathrm{ml}^{-1}$ in W5 solution after counting cells under the microscope $(\times 100)$ using a hemacytometer. Rest the protoplasts by keeping on ice for 30 min.

$\triangle$ CRITICAL STEP If cold response is desired, keep protoplasts at room temperature. Although the protoplasts can be kept on ice for at least $24 \mathrm{~h}$, freshly prepared protoplasts should be used for the study of gene expression regulation, signal transduction and protein trafficking, processing and localization.

12| Protoplasts should begin to settle at the bottom of the tube by gravity after $15 \mathrm{~min}$. Remove the W5 solution as much as possible without touching the protoplast pellet. Re-suspend protoplasts at $2 \times 10^{5} \mathrm{ml}^{-1}$ in MMG solution kept at room temperature.

DNA-PEG-calcium transfection $\bigcirc$ TIMING Less than $1 \mathrm{~h}$ for 20 samples

13. Add $10 \mu \mathrm{l}$ DNA (10-20 $\mu \mathrm{g}$ of plasmid DNA of 5-10 kb in size) to a 2-ml microfuge tube.

$\triangle$ CRITICAL STEP To study the role of a candidate regulator, three plasmids expressing a regulatory effector, a specific reporter and a transfection control reporter are used at the ratio of 5:4:1. However, it is highly recommended to optimize the plasmid ratio depending on each reporter's sensitivity. For example, a highly sensitive reporter needs only half the amount. Whenever the plasmid amount is changed, the same total plasmid DNA amount is compensated with a control plasmid that does not express any effector or reporter. The plasmid DNA has to be purified appropriately to support high transfection efficiency. Additional information on the preparation of plasmid DNA using the economical CsCl gradient is provided on the Sheen lab website (http://genetics.mgh. harvard.edu/sheenweb/protocols.html).

14| Add $100 \mu$ l protoplasts $\left(2 \times 10^{4}\right.$ protoplasts $)$ and mix gently.

15| Add $110 \mu \mathrm{l}$ of PEG solution, and then mix completely by gently tapping the tube (handle six to ten samples for each transfection). 
16| Incubate the transfection mixture at room temperature for up to $15 \mathrm{~min}$ (5 $\mathrm{min}$ is sufficient). $\triangle$ CRITICAL STEP Transfection time should be optimized empirically.

17| Dilute the transfection mixture with $400-440 \mu \mathrm{l}$ W5 solution at room temperature and mix well by gently rocking or inverting the tube to stop the transfection process.

18| Centrifuge at $100 \mathrm{~g}$ for 2 min at room temperature using a bench-top centrifuge and remove supernatant.

19| Re-suspend protoplasts gently with $1 \mathrm{ml}$ WI in each well of a 6-well tissue culture plate.

$\triangle$ CRITICAL STEP We also use 12-well (0.5 ml WI) or 24-well ( $0.25 \mathrm{ml} \mathrm{WI)} \mathrm{plates} \mathrm{for} \mathrm{larger-scale} \mathrm{experiments} \mathrm{(50-100} \mathrm{samples).}$ The culture plate is normally coated with $5 \%$ (vol/vol) sterile calf serum for a short time (1-2 s) to prevent sticking of the protoplasts to the plastic surface. The depth of the WI solution is approximately $0.1 \mathrm{~mm}$ to prevent hypoxia stress during protoplast incubation.

$\triangle$ CRITICAL STEP The use of carrier DNA is unnecessary for this type of DNA delivery.

$\triangle$ CRITICAL STEP High transfection efficiency can be achieved using 10-20\% PEG final concentration. The optimal PEG concentration should be determined empirically for each experimental purpose. Visual reporters such as GFP can be used to determine optimal DNA transfection conditions (Fig. 1d, Table 1). If protoplasts are derived from healthy leaf materials, most protoplasts should remain intact throughout the isolation, transfection, culture and harvesting procedures.

$\triangle$ CRITICAL STEP Protoplast transfection can be scaled up or down depending on the experimental needs. Approximately $10^{3-4}$ protoplasts are sufficient for reporter enzyme assays, $10^{4-5}$ protoplasts are required for protein labeling and immunoprecipitation or western blot analysis and $10^{6}$ protoplasts for RNA extraction and microarray analysis. If the protoplast transfection efficiency is low (less than $20 \%$ ), the quality of plasmid DNA or the ratio of plasmid DNA and protoplast number should be systematically examined to find the optimal condition.

? TROUBLESHOOTING

\section{Protoplast culture and harvest $\bigcirc$ TIMING 2-24 h}

20| Incubate protoplasts at room temperature $\left(20-25^{\circ} \mathrm{C}\right)$ for the desired period of time.

$\triangle$ CRITICAL STEP A stimulus can be applied during the incubation according to the experimental purposes. For example, the synthetic flg22 peptide derived from bacteria can be added for $10 \mathrm{~min}$ or $1 \mathrm{~h}$ for the analysis of protein kinase activity or early transcription responses, respectively. For the inducible gene expression system (Fig. 2c,d), DEX can be added to the protoplasts 15-30 min after DNA transfection.

$\triangle$ CRITICAL STEP In general, the protoplast incubation time is 2-6 $\mathrm{h}$ for RNA analysis and 2-16 $\mathrm{h}$ for enzyme activity analysis and protein labeling. The TEAMP system is most suitable for the study of early events in signal transduction pathways, gene regulation and cell death.

$\triangle$ CRITICAL STEP The protoplast incubation temperature has to be optimized according to experimental needs.

$\triangle$ CRITICAL STEP It is not necessary to perform experiments under sterile conditions in general. Ampicillin $\left(50 \mu \mathrm{g} \mathrm{m}^{-1}\right) \mathrm{can} \mathrm{be}$ added during the protoplast incubation after DNA transfection if bacterial growth is a concern.

21| Re-suspend and harvest protoplasts by centrifugation at $100 \mathrm{~g}$ for $2 \mathrm{~min}$.

22| Remove the supernatant and freeze samples on dry ice.

PAUSE POINT Samples can be stored at $-80{ }^{\circ} \mathrm{C}$ until further analysis.

\section{Reporter assays $\bigcirc$ TIMING 1-2 h}

23| Several assays can be carried out using option A (LUC assay), B (GUS assay) or C (GFP assay).

(A) LUC assay

(i) Add $100 \mu \mathrm{l}$ of protoplast lysis buffer to the frozen protoplasts and mix vigorously by vortexing for $2 \mathrm{~s}$ to rupture the protoplasts.

(ii) After 5 min incubation on ice, centrifuge at $1,000 \mathrm{~g}$ for $2 \mathrm{~min}$.

(iii) Use 5-20 $\mu$ l of the lysate and $100 \mu \mathrm{L}$ LUC mix (Promega) to measure LUC activity with a luminometer.

\section{(B) GUS assay}

(i) Add $10 \mu \mathrm{l}$ of the protoplast lysate from Step 23A(ii) into $100 \mu \mathrm{l}$ of MUG substrate mix and incubate for 30-180 min at $37^{\circ} \mathrm{C}$.

(ii) Add $0.9 \mathrm{ml} 0.2 \mathrm{M} \mathrm{Na}_{2} \mathrm{CO}_{3}$ to stop the reaction.

(iii) Measure the fluorescence of $\mathrm{MU}$ using a fluorometer.

$\triangle$ CRITICAL STEP Further dilution with $0.2 \mathrm{M} \mathrm{Na}_{2} \mathrm{CO}_{3}$ for GUS assay should be determined empirically.

\section{(C) GFP assay}

(i) View live cellular image of GFP or GFP fusion proteins (using protoplasts obtained in Step 22) under fluorescence microscopy $(\times 400-600)$ without any additional sample preparation steps. 


\section{TIMING}

Step 1: 3-4 weeks

Steps 2-4: approximately $1 \mathrm{~h}$ (depending on numbers of leaves being collected)

Steps 5-12: approximately 3-4 h (depending on Arabidopsis accession and mutants)

Steps 13-19: approximately $1 \mathrm{~h}$ (depending on numbers of samples being transfected)

Steps 20-22: approximately 2-24 h

Step 23: approximately $1-2 \mathrm{~h}$

\section{? TROUBLESHOOTING}

Troubleshooting advice can be found in Table 2 .

TABLE 2 | Troubleshooting table.

\begin{tabular}{lll}
\hline Problem & Possible reason & Solution \\
$\begin{array}{l}\text { Low protoplast } \\
\text { yield }\end{array}$ & Accession & $\begin{array}{l}\text { Arabidopsis growth condition is dependent on the accession used. As leaves before } \\
\text { bolting are used, Col and Ler plants grown under a relatively shorter photoperiod } \\
(10-13 \mathrm{~h}) \text { perform better in protoplast isolation }\end{array}$ \\
& Poor plant growth & $\begin{array}{l}\text { Check the quality of seeds (growth and storage conditions) and soil. We have had } \\
\text { problems with different types of soil occasionally. The quality of soil may vary from } \\
\text { batch to batch }\end{array}$ \\
& $\begin{array}{l}\text { Check and optimize growth conditions: temperature, humidity, light intensity, } \\
\text { photoperiod, watering and nutrients }\end{array}$ \\
& $\begin{array}{l}\text { Check leaf age, development and morphology (Fig. 1a) } \\
\text { Check activity of enzyme solution (enzyme quality and heat treatment) } \\
\text { Poor leaf condition }\end{array}$ \\
& Optimize leaf digestion time for each accession and mutant
\end{tabular}

$\begin{array}{lll}\begin{array}{ll}\text { Low transfection } \\ \text { efficiency }\end{array} & \text { PEG solution problem } & \text { PEG quality depends on sources and storage. Do not autoclave PEG solution } \\ & \text { Low-quality DNA } & \text { We use the economical CsCl gradient method for plasmid DNA purification. The detailed } \\ & \text { protocol is available on the Sheen lab website } \\ & \text { Protoplast/DNA ratio } & \text { Ratio should be determined empirically } \\ \text { Poor protoplast quality } & \text { Optimize conditions and the time for protoplast resting, response and incubation } \\ \text { Stimuli application } & \text { We always test and optimize the response timing and analyze broad concentrations of } \\ & \text { signal dosage to cover a wide range when a new signal is applied for the first time }\end{array}$

\section{ANTICIPATED RESULTS}

Protoplast transfection efficiency is approximately $60-90 \%$ with this protocol in general (Fig. 1d). It is necessary to have higher than $50 \%$ transfection efficiency for a reliable analysis. A typical use of the TEAMP assay is to determine the regulatory function of an effector using the readout of a specific reporter in cell-autonomous responses. The effect of regulatory candidates that are transfected with a specific reporter (Table 1) can be quantified within 2-12 h after transfection of mesophyll protoplasts. The specific reporter readout value should be normalized with that of a co-transfected control reporter driven by a constitutive promoter, e.g., UBQ10-GUS-NOS ${ }^{8}$.

ACKNOWLEDGMENTS We thank former and current members of the Sheen laboratory for their efforts to test and improve the TEAMP system. This work has been supported by grants from the National Science Foundation (IOB-0217191 DBI-0077692 and IOB-0618292) and National Institutes of Health (R01 GM060493) to J.S.

COMPETING INTERESTS STATEMENT The authors declare no competing financial interests.

Published online at http://www.natureprotocols.com Rights and permissions information is available online at http://npg.nature.com/ reprintsandpermissions

1. Sheen, J. Signal transduction in maize and Arabidopsis mesophyll protoplasts. Plant Physiol. 127, 1466-1475 (2001).

2. Cocking, E.C. A method for the isolation of plant protoplasts and vacuoles. Nature 187, 927-929 (1960).

3. Jacobsen, J.V. \& Beach, L.R. Control of transcription of $\alpha$-amylase and rRNA genes in barley aleurone protoplasts by gibberellin and abscisic acid. Nature $\mathbf{3 1 6}$, 275-277 (1985).
4. Assmann, S.M., Simoncini, L. \& Schroeder, J.I. Blue light activates electrogenic ion pumping in guard cell protoplasts of Vicia faba. Nature 318, 285-287 (1985).

5. Kovtun, Y., Chiu, W.L., Tena, G. \& Sheen, J. Functional analysis of oxidative stress-activated mitogen-activated protein kinase cascade in plants. Proc. Natl. Acad. Sci. USA 97, 2940-2945 (2000).

6. Sheen, J. Protein phosphatase activity is required for light-inducible gene expression in maize. EMBO J. 12, 3497-3505 (1993).

7. Luehrsen, K.R., de Wet, J.R. \& Walbot, V. Transient expression analysis in plants using firefly luciferase reporter gene. Methods Enzymol. 216, 397-414 (1992).

8. Norris, S.R., Meyer, S.E. \& Callis, J. The intron of Arabidopsis thaliana polyubiquitin genes is conserved in location and is a quantitative determinant of chimeric gene expression. Plant Mol. Biol. 21, 895-906 (1993).

9. Worley, C.K. et al. Degradation of Aux/IAA proteins is essential for normal auxin signalling. Plant J. 21, 553-563 (2000).

10. Tao, L., Cheung, A.Y., Nibau, C. \& Wu, H. RAC GTPases in tobacco and Arabidopsis mediate auxin-induced formation of proteolytically active nuclear protein bodies that contain AUX/IAA proteins. Plant Cell 17, 2369-2383 (2005). 
11. Wang, S., Tiwari, S.B., Hagen, G. \& Guilfoyle, T.J. Auxin response factor7 restores the expression of auxin-responsive genes in mutant Arabidopsis leaf mesophyll protoplasts. Plant Cell 17, 1979-1993 (2005).

12. Yanagisawa, S., Yoo, S.-D. \& Sheen, J. Differential regulation of EIN3 stability by glucose and ethylene signalling in plants. Nature 425, 521-525 (2003).

13. Hwang, I. \& Sheen, J. Two-component circuitry in Arabidopsis cytokinin signal transduction. Nature 413, 383-389 (2001).

14. Mueller, B. \& Sheen, J. Arabidopsis cytokinin signalling pathway. Sci. STKE 2007 (Connections Map Pathways, in the press), http://stke.sciencemag.org/cgi/cm/ stkmcm;CMP_10021 (2007).

15. Asai, T. et al. MAP kinase signalling cascade in Arabidopsis innate immunity. Nature 415, 977-983 (2002).

16. He, P. et al. Specific bacterial suppressors of MAMP signalling upstream of MAPKKK in Arabidopsis innate immunity. Cell 125, 563-575 (2006).

17. Cho, Y.-H., Yoo, S.-D. \& Sheen, J. Regulatory functions of nuclear hexokinase1 complex in glucose signalling. Cell 127, 579-589 (2006).

18. Ehlert, A. et al. Two-hybrid protein-protein interaction analysis in Arabidopsis protoplasts: establishment of a heterodimerization map of group $C$ and group $S$ bZIP transcription factors. Plant J. 46, 890-900 (2006).

19. Chiu, W. et al. Engineered GFP as a vital reporter in plants. Curr. Biol. 6, 325-330 (1996).

20. Lee, Y., Kim, D., Kim, Y. \& Hwang, I. Identification of a signal that distinguishes between the chloroplast outer envelope membrane and the endomembrane system in vivo. Plant Cell 13, 2175-2190 (2001).
21. Jin, J.B et al. A new dynamin-like protein, ADL6, is involved in trafficking from the trans-Golgi network to the central vacuole in Arabidopsis. Plant Cell 13, 1511-1526 (2001).

22. Sohn, E.J. et al. Rha1, an Arabidopsis Rab5 homolog, plays a critical role in the vacuolar trafficking of soluble cargo proteins. Plant Cell 15, 1057-1070 (2003).

23. Kim, H., Park, M., Kim, S. \& Hwang, I. Actin filaments play a critical role in vacuolar trafficking at the Golgi complex in plant cells. Plant Cell 17, 888-902 (2005).

24. Birnbaum, K. et al. A gene expression map of the Arabidopsis root. Science $\mathbf{3 0 2}$, 1956-1960 (2003).

25. Boudsocq, M., Barbier-Brygoo, H. \& Lauriere, C. Identification of nine sucrose nonfermenting 1-related protein kinases 2 activated by hyperosmotic and saline stresses in Arabidopsis thaliana. J. Biol. Chem. 279, 41758-41766 (2004).

26. Picard, D., Salser, S.J. \& Yamamoto, K.R. A movable and regulable inactivation function within the steroid binding domain of the glucocorticoid receptor. Cell 54, 1073-1080 (1988).

27. Asai, T. et al. Fumonisin B1-induced cell death in Arabidopsis protoplasts requires jasmonate-, ethylene-, and salicylate-dependent signaling pathways. Plant Cell 12, 1823-1835 (2000).

28. Wenck, A.R. \& Marton, L. Large-scale protoplast isolation and regeneration of Arabidopsis thaliana. Biotechniques 18, 640-643 (1995).

29. Damm, B., Schmidt, R. \& Willmitzer, L. Efficient transformation of Arabidopsis thaliana using direct gene transfer to protoplasts. Mol. Gen. Genet. 217, 6-12 (1989).

30. Masson, J. \& Paszkowski, J. Culture response of Arabidopsis thaliana protoplasts is determined by growth conditions of donor plants. Plant J. 2, 829-833 (1992). 


\section{Corrigendum: Arabidopsis mesophyll protoplasts: a versatile cell system for transient gene expression analysis}

Sang-Dong Yoo, Young-Hee Cho \& Jen Sheen

Nat. Protoc. 2, 1565-1572 (2007); doi:10.1038/nprot.2007.199; published online 21 June 2007; corrected after print 11 0ctober 2013

In the version of this article initially published, the concentration given for $2.5 \mathrm{mM}$ Tris-phosphate (pH 7.8) when making up protoplast lysis buffer was incorrect. The correct concentration should be $25 \mathrm{mM}$. The error has been corrected in the HTML and PDF versions of the article. 